\title{
The Impact of Integrating Phase Change Material upon Indoor Air Temperature in Hot Climates
}

\author{
MENNATALLAH HASSAN YOUSSEF MOHAMED \\ Department of Architecture \\ The British University in Egypt \\ El Sherouk City, Egypt \\ EGYPT \\ MOSTAFA RIFAT \\ Department of Architecture \\ Ain Shams University, EGYPT \\ KHALED DEWIDAR \\ Department of Architecture \\ The British University in Egypt, EGYPT
}

\begin{abstract}
The aim of this paper is to identify the effect of PCM as a building material of commercial building envelope on the indoor air temperature within a hot climatic context as Egypt. This paper will expose the potentials of using Phase Change Material (PCM) as an integral part of the building process to save energy, where it first introduces the current environmental challenges and identifies the impact of Thermal Energy Storage as a sustainable approach. Two different types of PCM will be tested in an experimental space in Egypt on different building model orientations and different PCM allocations, to test their effect on indoor air temperature. This will be practically examined by DesignBuilder simulation, to explore the possibilities of improving indoor thermal comfort within the studied types. Finally, conducting a set of recommendations for PCM application as a building material within the Egyptian context.
\end{abstract}

Key-words: Thermal energy storage, Phase change material, Building orientation, Indoor air temperature, Design Builder Energy Simulation.

Received: May 9, 2021. Revised: November 18, 2021. Accepted: December 17, 2021. Published: January 13, 2022.

\section{Introduction}

The globe has been forced into a huge environmental problem as a result of a rapid growth in global population paired with a high rise in energy demand. A dramatic increase in the world population combined with a strong rise in energy demand has directed the world to significant environmental challenge that already shows a clear beginning[1]. The question arises as to whether our planet has enough resources to satisfy our current and future demand for raw materials and primary energies. In the building sector a more innovative solutions are required to reduce the consumed energy. Apart from the implementation of sustainable settings in buildings, the reliance on air cooling in hot climes has expanded considerably in the recent decade, resulting in enormous demands on electric power and less concern for preserving fossil fuels. The amount of energy consumed varies significantly between day and night, depending on the demand of the building's activity sector. In hot regions, air conditioning accounts for the majority of load variance [2]. In this era of building energy efficiency, all attention is focused on lowering energy consumption and peak power demand associated with building operations [3].The difficulty of maintaining thermal comfort for individuals inside buildings is complicated by daily fluctuations in temperature and solar radiation. Buildings that are passive or energy-conserving attempt to control the available thermal energy in order to ensure human comfort[4].

Buildings in hot climates need high energy to cool the building and reach better thermal comfort 
inside. The high temperatures in Egypt cause an increase in electricity depletion throughout the summer. According to Egypt's state-run National Energy Control Center, they were compelled to minimize the pressure on the electricity grid, and citizens were urged to control their use of electricity, particularly the use of air conditioners and heaters, and that was in 2013[5].

Accordingly, new aspects in building envelope have emerged to reduce the total heat gain inside the commercial buildings and increase the inside comfort with less demand on HVAC systems. One of these aspects is the Phase Change material PCM, which is considered a "Thermal energy storage" (TES) through the building skin, that can maintain a sustainable environment by shifting the peak of energy use of the building to a later time, reducing fossil fuel consumption, and rationalizing the building operation energy[4].

\section{Thermal Energy Storage}

In cold and hot regions, the building envelope is a critical solution for reducing energy consumption, heating and cooling and achieving energy-efficient buildings. Cooling demand is predicted to increase by about 150 percent globally by 2050 , and by 300 percent to 600 percent in poorer countries[6]. Different solutions are recommended to minimize energy consumption in hot climates, such as passive techniques. Many techniques are currently under investigation to improve the thermal performance of the building envelope and increase its thermal storage capacity. These techniques, which are either implemented passively or actively, have shown advanced improvements in decreasing the heating and cooling loads and controlling the energy of the building. Reducing building energy use by up to $20 \%$ by 2030 is technically possible by using such cost-effective technologies [7].

New strategies for passive cooling are introduced through Thermal Energy Storage TES materials. Thermal Energy Storage (TES) includes two aspects; the storage of heat on one hand, and the storage of cold on the other hand. The aim of this storage is to limit the production of thermal mass. Heating and cooling usually take place when the electrical network is in a critical state. In this peak of electrical consumption, the pollution is maximized due to the use of most polluting thermal and electric plants, plants that are necessary to equalize the production with the consumption. The use of TES must be considered to cut off these peaks. TES performs many advantages, by shifting the production of heat or cold, it can result in a reduction of $\mathrm{CO}_{2}$ emissions. Moreover, as production is independent from consumption, other solutions for the production of heat and cold can be imagined, like solar energy or natural cooling during the night in summer. Among other advantages, TES also allows to reduce running costs[8].

Thermal energy storage for thermal purposes has gotten a lot of attention in recent decades, with a number of thermal energy storage systems developed as industrial countries became more electrified. Such thermal energy storage systems offer a huge potential for improving the efficiency of thermal energy equipment and permitting largescale energy substitutes from a cost perspective[9]. Energy storage comes in a variety of forms and plays a vital role in energy conservation. Thermal storage in a building could be critical for lowering cooling loads and lowering temperature rises[1].

\section{Phase Change Material}

The study of PCM for applications in building mass heating and cooling has a long history. M. Telkes researched the use of PCM to store solar heat and use it for room heating as early as the 1930s. Other scholars continued these investigations after the 1973 oil crisis. However, applications were still not cost-effective. The situation has begun to alter in the last decade as energy prices have risen. The demand for energy to maintain indoor thermal comfort has increased around the world, particularly for cooling and air conditioning[10].

People like to have room temperatures in a very narrow temperature range. In this case phase change materials can be used to control temperature swings or for energy storage with high storage density. Especially in buildings with low thermal mass, the temperature can change significantly, very quickly and therefore create an uncomfortable environment[11].

The thermal mass effect is more efficient the longer the time gap between storing heat and retransmitting it inside the building. Internal temperatures are thereby kept within human thermal comfort levels, resulting in lower heating and cooling loads and lower energy usage. 


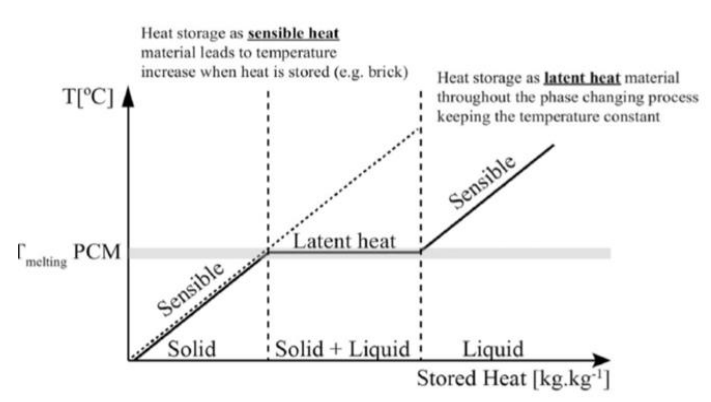

Fig. 1: Heat transition regions of PCM [15]

Therefore, applications for heating and cooling in buildings are expected to have large market potential for phase change materials. Phase Change Materials (PCM) are latent heat storage material[12].

At a generally constant temperature, phase change materials (PCMs) can absorb and release heat during phase transitions (mostly from the solid to the liquid state and vice versa) as shown in Fig. 1 . Furthermore, PCM's are used to shift peak-load to off-peak times, hence improving building efficiency[13][14].

In fact, because of its high energy storage density and isothermal behavior throughout the phase shift process, latent heat storage in a PCM is very interesting. As a result, heat generated during periods of sunshine can be recovered and used for air cooling in buildings [16].

When compared to a wall system without PCM and equal geometrical parameters and insulation material, simulations showed that using building materials with PCM improved energy performance [17]

PCM is an innovative way of increasing the thermal mass of a building structure and, as a result, the building's performance. PCM's are included into a building's design in a variety of ways and combinations to serve as part of the construction materials and to maximize the heat storage potential [18].

\section{Experimental Study}

This is the practical part of the research. It is meant to explore the possibilities for improving in door thermal comfort in buildings through thermal energy storage in building skin using PCM in the commercial building envelope, with different PCM properties in building orientations and different PCM allocations in building envelope.

\subsection{Building the Model}

The practical simulation is applied to an initial model, which is built upon the standards of the Egyptian code of commercial buildings. According to DOE (DOE, U.S Department of Energy, 2010), DesignBuilder is the first comprehensive user interface to the EnergyPlus dynamic thermal simulation engine, developed by DesignBuilder Software Ltd. to generate performance data, from climate and thermal characteristics of the materials data. The program allows the calculation of heating and cooling loads by the method adopted by ASHRAE and implemented in EnergyPlus [19].

According to Chandrashekaran, there are two ways for modeling in DesignBuilder software, namely; "building block" and "component block". In the "building block" modeling approach, the program automatically defines indoor areas and focuses on different parameters for environmental simulation within. Where using this approach, thermal analysis addresses the effects of the different building component, such as the effect of roof, floors, and walls on indoor thermal comfort within the test zone. On the other hand, modeling by "component block" is less efficient when it's used for thermal analyses. In this modeling approach, building elements like walls are defined as independent components. Thus, "Component block" cannot be used for the present thermal analysis, where it only allows for examining the effect of walls as individual objects neglecting their thermal impact on indoor thermal tests [20]. Therefore, the "building block" approach gives the accurate results required for the present study, particularly with the complexity and multiplicity of examined variables/cases. Hence, the forthcoming simulations are done using this approach to examine the impact of six different vertical greening systems upon indoor thermal behavior.

The practical simulation were applied to an initial model, whose specifications are identified here under. Two different PCM material properties applied on four different building orientations with changing the alignment of PCM on each orientation of the initial model, to examine their individual impact upon the indoor thermal behavior. A major principle in selecting the material properties to be tested is according to the Egyptian Code, and the orientation variables are according to the heat gain produced on each elevation, that was determined through ecotect software. Organic PCM will be used in the simulation. A two-wall-cross section containing PCM will be examined on different building orientations. Each PCM will be applied to a wall with all other walls adiabatic, to examine the 
best performance for a material in the building envelope of commercial unit in Cairo, Egypt, where the used software is already equipped with the climatic settings of Egypt. The unit is adjusted to be commercial use due to the high consumption of commercial buildings in the peak hours.

The organization of commercial office space depends on human relationships and communication. Usable floor area is based on the principle of office units arranged in a row along the façade or some other variants; therefore the office size is determined through the unit of workstation and circulation. Most of the contemporary office furniture is rectangle in shape. Therefore, office space is usually rectangular in shape.

The present research uses PCM material in DesignBuilder as an inner layer of construction. As there is no plasterboards in Designbuilder that include PCM as the market. Therefore, they are

Table 1. Working space plan

\begin{tabular}{ll}
\hline Location & Cairo, Egypt \\
\hline Height & $3 \mathrm{~m}$ \\
\hline Width & $3.86 \mathrm{~m}$ \\
\hline Length & $6.56 \mathrm{~m}$ \\
\hline Total floor area & $25 \mathrm{~m}^{2}$ \\
\hline
\end{tabular}

examined as two excessive materials attached to each other to maintain the nearest results. Based on a previous research conducted by Konstantinidou, the simulation of PCM using DesignBuilder is not that accurate because PCM does not only depend on the material property, but the enthalpy and melting point of it that affects the whole performance of the material and its effect on the interior temperature[20]. Now PCM is included as a material with all its properties that can be tested more accurately than any previous simulation. The proposed initial model comprises a single working space that is $25.7 \mathrm{~m}^{2}$ in a single-story building; it is proposed to be rectangular as a widely used building form. Hence, its dimensions. Hence, its dimensions worked out as $6.6 \mathrm{~m}(\mathrm{~L}) \times 3.9 \mathrm{~m}(\mathrm{~W}) \times 3 \mathrm{~m}(\mathrm{H})$ as seen

Fig. 2 and Table 1.

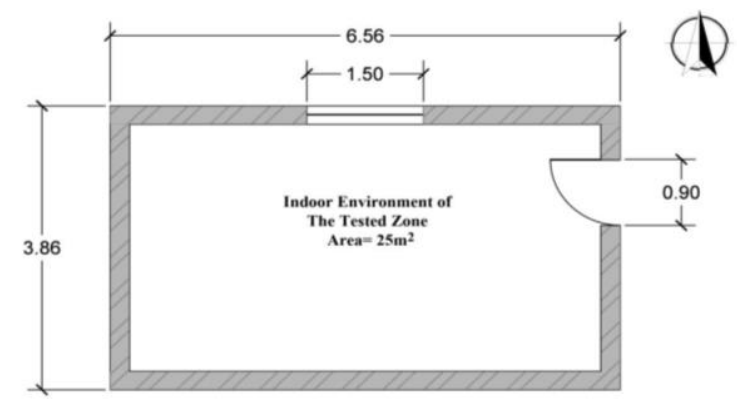

Fig. 2: Tested model building block

Table 2. Conventional wall layers

\begin{tabular}{lll|l}
\hline $\begin{array}{l}\text { Layers from outermost to } \\
\text { innermost }\end{array}$ & $\begin{array}{l}\text { Thickness } \\
(\mathbf{m})\end{array}$ & Resistance $\left.\mathbf{~} \mathbf{m}^{\mathbf{2}} \mathbf{- K} / \mathbf{W}\right)$ & Visualization \\
\hline Plaster & 0.05 & 0.15 & \\
\hline Mortar & 0.02 & 0.15 \\
\hline Brick & 0.25 & 0.54 \\
\hline Mortar & 0.02 & 0.15 \\
\hline Plaster & 0.05 & 0.15 \\
\hline Total & 0.39 & 1.14 \\
\hline
\end{tabular}

Table 3 Ground floor layers

\begin{tabular}{|c|c|c|c|c|}
\hline $\begin{array}{l}\text { Layers from outermost to } \\
\text { innermost }\end{array}$ & $\begin{array}{l}\text { Thickness } \\
\text { (m) }\end{array}$ & $\begin{array}{l}\text { Resistance } \\
\left(\mathbf{m}^{2}-\mathbf{K} / \mathbf{W}\right)\end{array}$ & & \\
\hline Concrete & 0.20 & 0.34 & & \\
\hline Damp proof course (DPC) & 0.02 & 0.23 & Granite & Mortar \\
\hline Screed & 0.05 & 0.15 & $\begin{array}{c}\text { Sand } \\
\text { D.P.C }\end{array}$ & Screed \\
\hline Sand & 0.06 & 0.15 & & Plain \\
\hline Mortar & 0.02 & 0.15 & & \\
\hline Granite & 0.02 & 0.32 & & \\
\hline
\end{tabular}


Table 4. Roof Layers

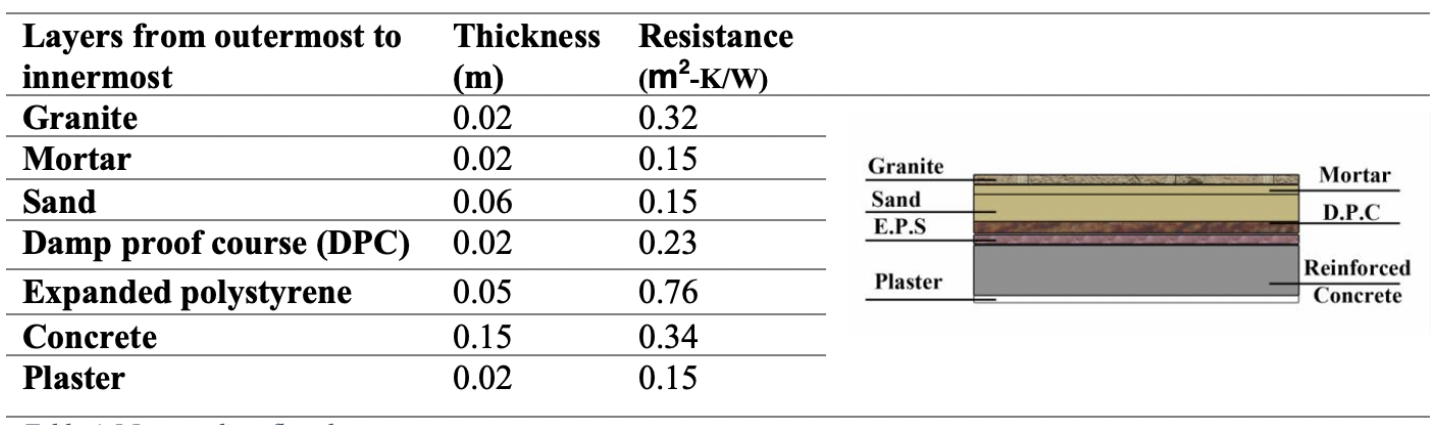

Table 5. Intermediate floor layer

\begin{tabular}{|c|c|c|c|c|}
\hline $\begin{array}{l}\text { Layers from outermost } \\
\text { to innermost }\end{array}$ & $\begin{array}{l}\text { Thickness } \\
\text { (m) }\end{array}$ & $\begin{array}{l}\text { Resistance } \\
\left(\mathrm{m}^{2}-\mathrm{K} / \mathbf{W}\right)\end{array}$ & & \\
\hline Granite & 0.02 & 0.32 & & \\
\hline Mortar & 0.02 & 0.15 & $\begin{array}{l}\text { Granite } \\
\text { Sand }\end{array}$ & Mortar \\
\hline Sand & 0.06 & 0.15 & & \\
\hline Concrete & 0.15 & 0.34 & Plaster & $\exists$ Koncrete \\
\hline Plaster & 0.02 & 0.15 & & \\
\hline
\end{tabular}

All building materials for the model are built according to the Egyptian Code to Improve Building Energy Efficiency ECIBEE[21].

Table 2 shows the conventional way to build exterior walls of commercial buildings in Egypt. Table 3 shows the ground floor layers. Table 4 shows the roof layers, and Table 5 shows the intermediate floor layers in Egypt.

\subsection{Applying PCM to the Model}

The organic PCM is widely known as BioPCM; it works in the daytime by absorbing heat from solar and internal gains and then releasing that heat during the night in order to reduce cooling and heating loads along with energy consumption, while enhancing comfort in the process.

BioPCM products are stocked by the following categories:

- Q-Values: peak melting temperatures in degrees Celsius $23^{\circ} \mathrm{C}, 25^{\circ} \mathrm{C}$ and $27^{\circ} \mathrm{C}$.

- M-Values: Btu thermal energy storage capacity of M27, M51, M91 and M 128

- Plasterboard Length: $1.22-2.44 \mathrm{~m}$

\section{- Plasterboard width: $0.42 \mathrm{~m}$}

Generally, the HVAC thermostatic controls per QValue. Whenever the $M$ value increases, thermal energy storage for every square meter increases.

The initial model will be examined in the light of different PCM properties on different walls with different façade orientation, the tested variables will be the thermal energy storage capacity of PCM (M value) and the location of the wall that contains PCM on different walls of each orientation of the building. The selected PCM is an organic phase change material. This wall composition is selected in accordance to the heat gain of each elevation on the different orientations of the model. The model will test 2 different PCM specifications on the building wall.

Table 6 and Table 7 show the wall section containing PCM.

\subsection{Applying PCM to Different Orientations}

The building has different heat again on each elevation according to the sun-path movement. The solar radiation differs from different climatic zones and different wall orientations. The building orientation is one of the key factors that affect the building performance; especially when using different materials to the building envelope; the building thermally may react differently. 
Good orientation is a low-cost way to improve occupant thermal comfort while also saving money on cooling and heating. A suitable building orientation will allow the building to receive the desirable winter light while also allowing for summer ventilation by facing the summer wind stream [22].
Therefore, the model will shift four different orientations with different PCM allocation according to solar radiation. The simulation of the four building orientations that will be presented are: model (A), model (B), model (C) and model (D) as shown in Table 8

Table 6. Wall layers using PCM (1) M91/Q27

\begin{tabular}{|c|c|c|c|}
\hline $\begin{array}{l}\text { Layers from } \\
\text { outermost to } \\
\text { innermost }\end{array}$ & Thickness & $\begin{array}{l}\text { Resistance (m²- } \\
\text { K/W) }\end{array}$ & $\begin{array}{l}\text { Brick } \\
\text { PCM }\end{array}$ \\
\hline Plaster & 0.05 & 0.15 & \\
\hline Mortar & 0.02 & 0.15 & Plaster- \\
\hline Brick & 0.25 & 0.54 & board \\
\hline PCM M91/Q27 & 0.0074 & N.A. & \\
\hline Plasterboard & 0.012 & 0.15 & \\
\hline
\end{tabular}

Table 7. Wall layers using PCM (2) M182/Q27

\begin{tabular}{|c|c|c|c|}
\hline $\begin{array}{l}\text { Layers from outermost to } \\
\text { innermost }\end{array}$ & Thickness & $\begin{array}{l}\text { Resistance }\left(\mathbf{m}^{2}-\right. \\
\text { K/W) }\end{array}$ & Brick \\
\hline Plaster & 0.05 & 0.15 & PCM \\
\hline Mortar & 0.02 & 0.15 & \\
\hline Brick & 0.25 & 0.54 & $\begin{array}{l}\text { Plaster- } \\
\text { board }\end{array}$ \\
\hline PCM M182/Q27 & 0.012 & N.A. & \\
\hline Plasterboard & 0.012 & 0.15 & \\
\hline
\end{tabular}

Table 8. Four different building orientation

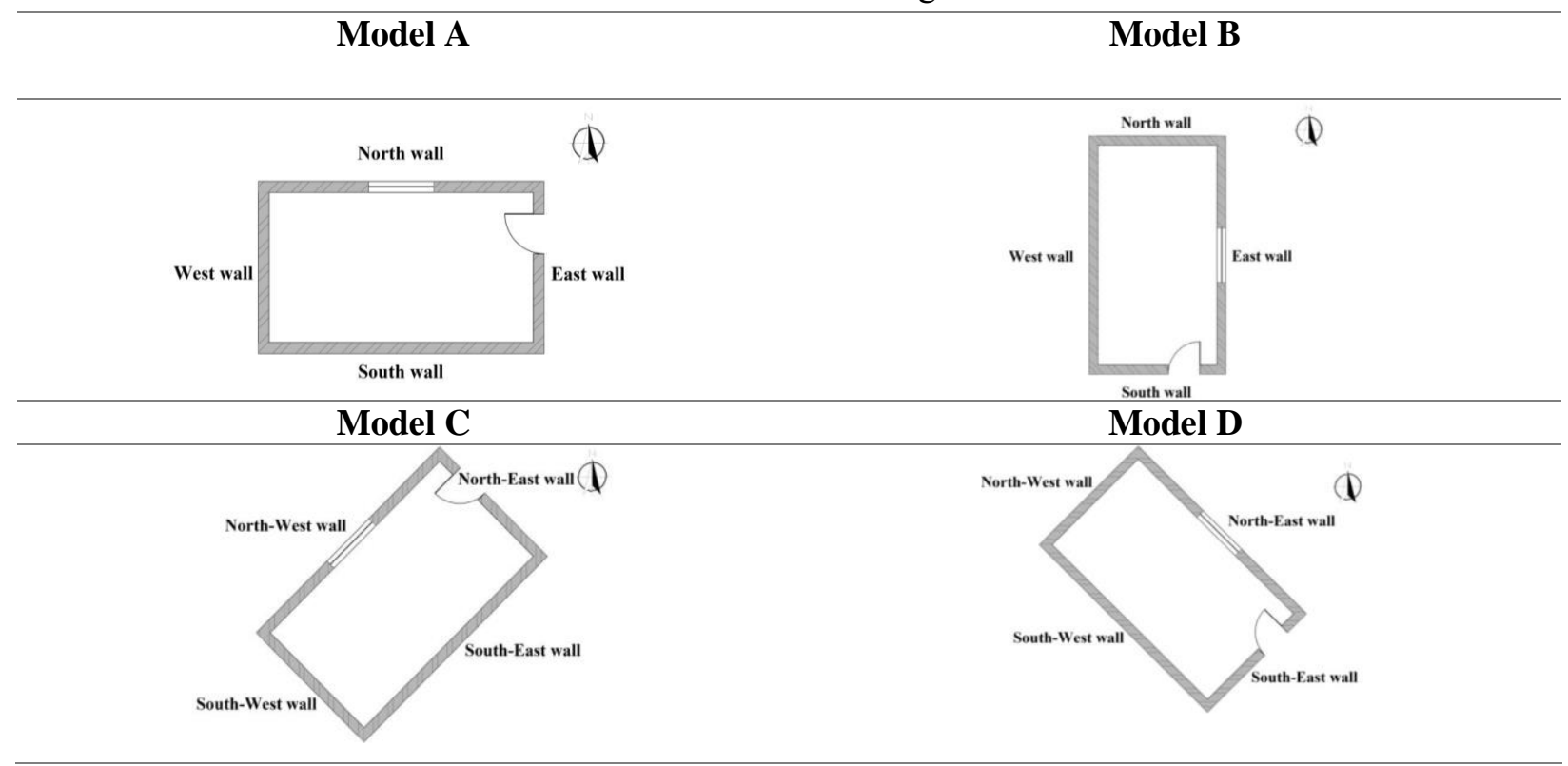

After a brief introduction to DesignBuilder, the technical constraints were synthesized with findings from the preceding theoretical part towards setting the primary model, upon which PCM variables will be applied. 
These variables include different melting temperatures for PCM (M value), building orientation, and PCM alignment on different façades. Different facade orientations were suggested to examine applying different PCM's as shown in

Table 8 .

For PCM systems, they were mainly selected with two different $M$ values and constant $Q$ values with the same wall cross-section.

The building orientation varies among the four basic architectural designs to be tested. Eco-tect program was used to simulate the amount of heat gain on each façade to determine the efficient alignment of PCM on each wall when changing the orientation.
Therefore, facades with higher heat gain are examined.

There are four models with two different PCM's, aligning the PCM on six different walls according to the heat gain resulting in twenty-four simulations for each type of PCM. All of these simulations are tested on the four days of the year $\left(21^{\text {st }}\right.$ of March, June, September and December) that present each season.

In this sense, the two different PCM systems will be applied to four building orientations with six different alignments of the PCM wall and compared to the initial case as shown in Fig. 3.

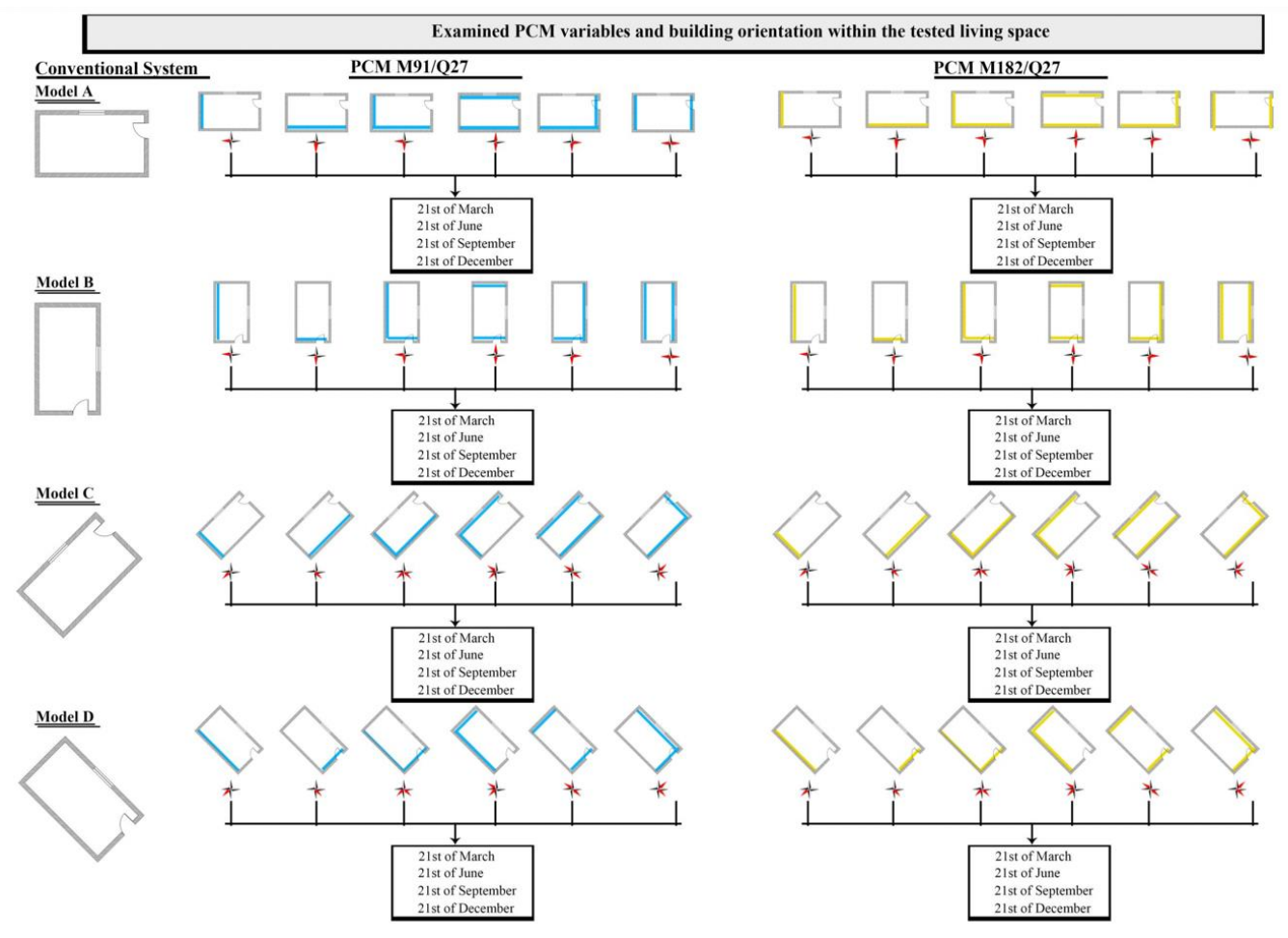

Fig. 3: Modeled variables for the tested commercial space by Design Builder

\section{Simulation and Results}

This section is meant to report, analyze, interpret, and discuss the results of DesignBuilder simulation in relation to the different variables outlined earlier, to learn practically about the impact of these variables upon thermal comfort of a commercial space unit within the climatic settings of Egypt.
The conventional model was tested in DesignBuilder over the four models A, B,C and D on the four different days in the year, so as to compare afterwards the impact of applying different $P C M$ 's on different orientations upon indoor thermal comfort. Thermal simulations for conventional model $A, B, C$ and $D$ results are shown in

Table 9, which compares between the performances of the model on the four days to determine the best performance among all models. 
After applying PCM (1), which intended to achieve ideal thermal performances for the following four cases:

- Applying PCM 1 on the North and South façade of model $\mathrm{A}$ is considered the best performance among the other six alignments. This is due to the achievement of a temperature difference of up to $10^{\circ} \mathrm{C}$ less than the conventional model.

- Applying PCM 1 on the South and West façade of model $\mathrm{B}$ is considered the best performance among the other six alignments. This is due to the achievement of a temperature difference of up to 7 ${ }^{\circ} \mathrm{C}$ less than the conventional model.
- Applying PCM 1 on the North West and South East façade of model D is considered the best performance among the other six alignments. This is due to the achievement of a temperature difference up to $7^{\circ} \mathrm{C}$ less than the conventional model.

- Applying PCM 1 on the South East and South West façade of model D is considered the best performance among the other six alignments. This is due to the achievement of temperature difference up to $8{ }^{\circ} \mathrm{C}$ less than the conventional model.

Table 9. Comparison between the models A,B,C \& D with different PCM (1) alignment on different days of the year

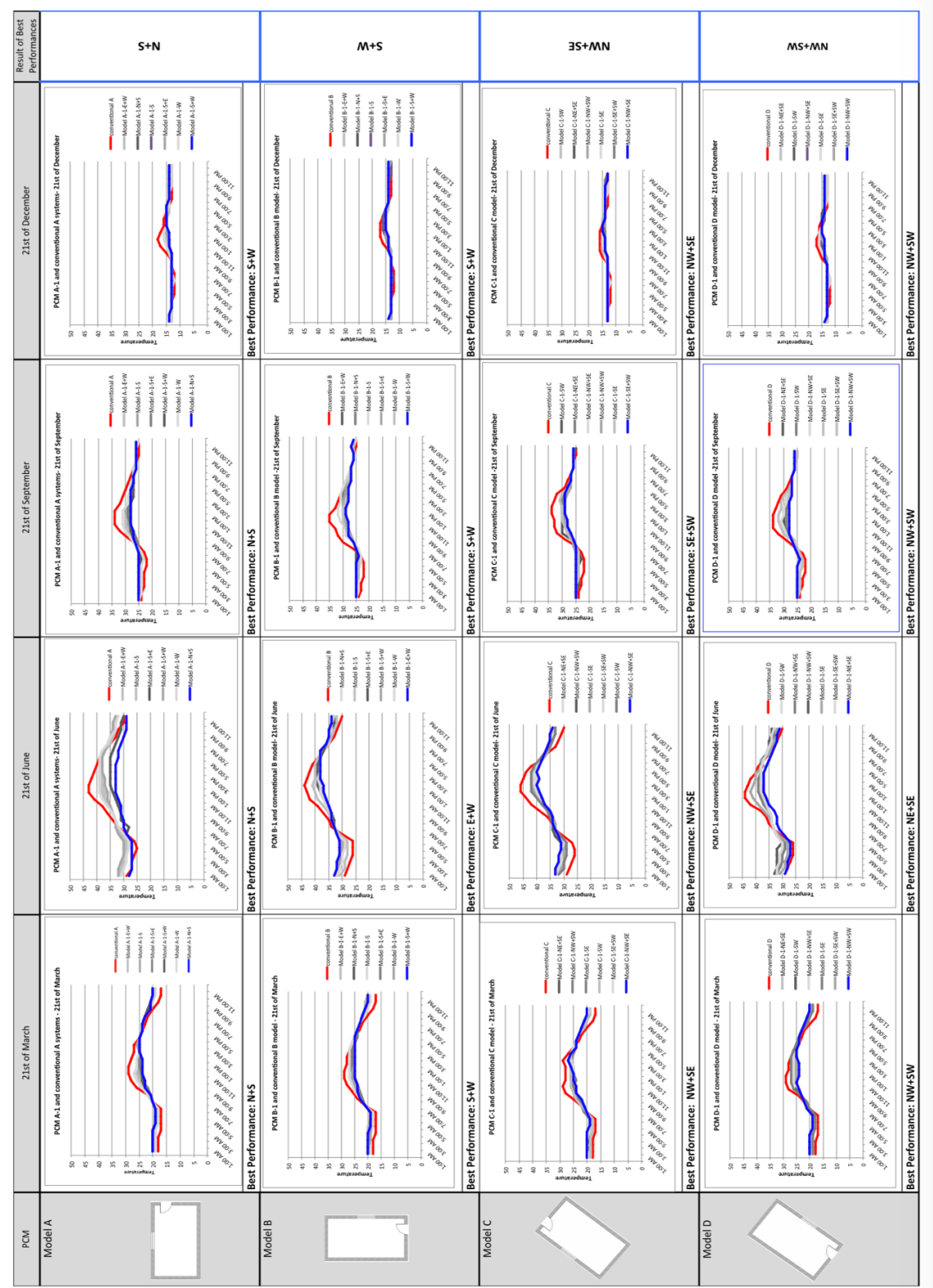


The results of PCM (2) - M182/Q27 model simulation were grouped in one analytical graph presenting the thermal behavior of the four days tested in the study. As a result one ideal case was selected from each graph based on the thermal performance and indoor thermal comfort achievement. Then this comparison is applied on the four models A,B,C and D. The result of this analysis is four preferred PCM alignment on facades from each model and this is illustrated in Table 10.

Table 10 compares between the performances of the models on the four days to determine the best performance among all models. After applying PCM (2), which intended to achieve ideal thermal performances for the following four cases:

- Applying PCM 2 on the North and South façade of model $\mathrm{A}$ is considered the best performance among the other six alignments. This is due to the achievement of temperature difference up to 12 ${ }^{\circ} \mathrm{C}$ less than the conventional model.
- Applying PCM 2 on the South and West façade of model $\mathrm{B}$ is considered the best performance among the other six alignments. This is due to the achievement of temperature difference up to 11 ${ }^{\circ} \mathrm{C}$ less than the conventional model.

- Applying PCM 2 on the North West and South East façade of model D is considered the best performance among the other six alignments. This is due to the achievement of a temperature difference of up to $10{ }^{\circ} \mathrm{C}$ less than the conventional model.

- Applying PCM 2 on the South East and South West façade of model D is considered the best performance among the other six alignments. This is due to the achievement of temperature difference of up to $11{ }^{\circ} \mathrm{C}$ less than the conventional model.

From the previous analysis, it was concluded that; PCM (2) model achieved better thermal performance than PCM (1) in comparison with conventional case. 
Table 10. Comparison between the models A,B,C \& D with different PCM (2) alignment on different days of the year

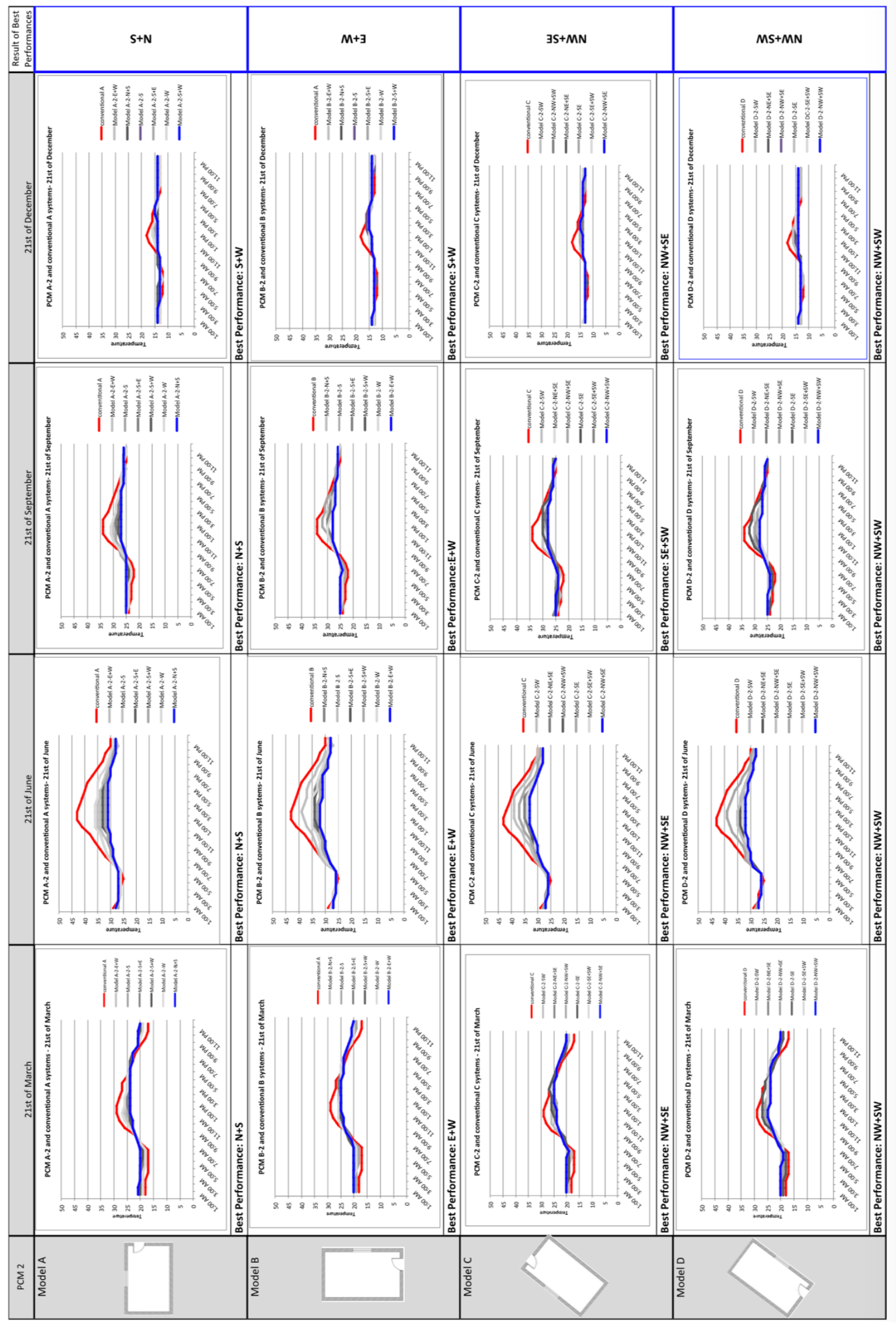




\section{Conclusion}

Applications of latent heat thermal energy storage in buildings have the ability to decrease the temperature in general and narrow the gap between the peak hours and off-peak to decrease the dependence on electricity.It also causes the reduction of indoor temperature fluctuation to achieve indoor comfort. Building orientations affect the behavior of thermal comfort. In hot climates it is better to orient the rectangular building, where the longer side extend through the North and South. The surface area of PCM on the walls affects overall performance. When PCM surface area is maximized, a reduction in indoor temperature takes place. This was validated in Models A and B where applying PCM on the wider, bigger surface area of the façade achieved the best thermal comfort. The ideal indoor air temperature is achieved when the building is oriented toward the East- West axis. The higher thermal energy storage capacity of PCM (M value) the greater cooling effect for the space. M128 with a higher $M$ value, achieved better thermal performance in hot climates than M91 with a lower $M$ value. PCM has a significant positive influence on indoor thermal comfort and moderating air temperature, compared to a bare wall as found from simulation tests.

\section{Future Research}

It is recommended to optimize PCM material on the building envelope, the initial cost and running cost. To be able to implement it in the commercial building envelope in an energy efficient way.

\section{References:}

[1] Dirk U.Hindrichs. (2007). Sustainable design in tropical and subtropical regions. unhabitat.

[2] Ravikumar, M., and PSS. Srinivasan. "NATURAL COOLING OF BUILDING USING PHASE CHANGE MATERIAL." International Journal of Engineering and Technology, vol. 5, no. No. 1, 2008, pp. 1-10., www.ijet.feiic.org/journals/J2008-V1001.pdf.

[3] Stetiu, Corina, and Helmut E. Feustel. "PhaseChange Wallboard and Mechanical Night Ventilation in Commercial Buildings." California Geothermal Energy Collaborative. Lawrence Berkeley National Laboratory, Berkeley, CA, Apr. 2011. Web. 17 Sept. 2020.

[4] Konstantinidou, Christina V. "Integration of Thermal Energy Storage in Buildings." Thesis.
The University of Texas at Austin, 2010. University of Texas. Center for Sustainable Development., Spring 2010. Web. 17 Sept. 2020.

[5] Ahramonline. "After Power Cuts, Egypt Govt Calls on Citizens to Ration Electricity." Business (2013): n. pag. Ahramonline. 2010 Ahram Online, 21 May 2013. Web. 21 Sept. 2020.

[6] IEA, Technology Roadmap, Energy efficent building envelopes. https://www.iea. org/reports/technology-roadmap-energyefficient-building-envelopes, 2013. Web. 7 Oct. 2020.

[7] DOE-USA, An assessment of energy technologies and research opportunities, chapter 5 increasing effic, Build. Syst. Technol (2015) 143-181. https://www.en ergy.gov/sites/prod/files/2017/03/f34/qtr-2015chapter5.pdf.

[8] Gravoille, Pauline. CASE STUDY OF ACTIVE FREE COOLING WITH THERMAL ENERGY STORAGE TECHNOLOGY. Thesis. KTH School of Industrial Engineering and Management Energy Technology, 2011. STOCKHOLM: Diva, n.d. Print.

[9] Dincer, I. (2010, November). Thermal Energy Storage: Systems and Applications (Vol. 2). Canada: Wiley.

[10] Konstantinidou, C. V. (2010). Integration of Thermal Energy Storage in Buildings. The University of Texas at Austin: Center for Sustainable Development.

[11] Ashmawy, Rania E., and Neveen Y. Azmy. "Buildings Orientation and Its Impact on the Energy Consumption." The Academic Research Community Publication, Ierek Press, 2018, https://press.ierek.com/index.php/ARChive/artic le/view/344.

[12] Harald Mehling, Luisa F. Cabeza, "Heat and cold storage with PCM : An Up to Date Introduction into Basics and Applications.", Springer edi- tions, 2008, pp. 6-9, 15-40, 218250, 274-280

[13] .V. Tyagi, A.K. Pandey, D. Buddhi, R. Kothari, Thermal performance assessment of encapsulated PCM based thermal management system to reduce peak energy demand in buildings, Energy Build. 117 (2016) 44-52, https://doi.org/10.1016/ j.enbuild.2016.01.042.

[14] Z.A.A.S. Al-Absi, M.H.M. Isa, M. Ismail, Application of phase change materials (PCMs) in building walls: a review, in: Int. Conf. Archit. Civ. Eng. Conf, Springer, 2018, pp. 73-82, https://doi.org/10.1007/978-981-13-2511-3_9. 
[15] C. Amaral, R. Vicente, P.A.A.P. Marques, A. Barros-Timmons, Phase change materials and carbon nanostructures for thermal energy storage: a literature review, Renew. Sustain. Energy Rev. 79 (2017) 1212-1228, https://doi.org/ 10.1016/j.rser.2017.05.093.

[16] Jmal, Imen, and Mounir Baccar. "Numerical Study of Thermal Performances of a PCM-AIR Solar Heat Exchanger." WSEAS TRANSACTIONS ON FLUID MECHANICS, Volume 13, 2018, 2018, www.wseas.org/multimedia/journals/fluid/2018/ a045913-219.pdf.

[17] DIACONU, BOGDAN, and MIHAI CRUCERU. Phase Change Material (PCM) Composite Insulating Panel with High Thermal Efficiency. Wseas, http://www.wseas.us/elibrary/conferences/2010/Bucharest/EEETE/EE ETE-17.pdf.

[18] M. Kheradmand, R. Vicente, M. Azenha, J.L.B. de Aguiar, Influence of the incorporation of phase change materials on temperature development in mortar at early ages: experiments and numerical simulation, Construct. Build. Mater. 225 (2019) 1036-1051, https://doi.org/10.1016/j.conbuildmat.2019.08.0 28.

[19] DesignBuilder, (2011). Building Performance Analysis Flyer. Available at: Energy Conservation through Energy Storage (ECES) Programme, International Energy Agency, Brochure: Jan. 2013. Web. 29 Nov. 2016.

$<$ http://www.ieaeces.org/files/090525_broschue re_eces.pdf. $/>$.

[20] Chandrashekaran, D., (2010). Air Flow through Louvered Openings: Effect of Louver Slats on Air Movement, Thesis submitted to the Faculty of the USC School of Architecture University of Southern California, in partial fulfillment of the requirements of the degree of Masters of Science in Architecture.

[21] ECIBEE, T. p. (2009). Egyptian code to improve building energy efficiency. Cairo: National Center for Housing and Construction Research.

[22] Ashmawy, Rania E., and Neveen Y. Azmy. "Buildings Orientation and Its Impact on the Energy Consumption." The Academic Research Community Publication, Ierek Press, 2018, https://press.ierek.com/index.php/ARChive/artic le/view/344.

\section{Creative Commons Attribution License 4.0 (Attribution 4.0 International, CC BY 4.0)}

This article is published under the terms of the Creative Commons Attribution License 4.0 https://creativecommons.org/licenses/by/4.0/deed.en 